\title{
A Prospective Study on Clinical Pattern of Hospital Acquired Pneumonia
} Dr. Saroja BG*

Associate Professor Department of Tb \& Chest the Oxford Medical College, Hospital \& Research Centre, Bengaluru, India

DOI: $10.36347 /$ sasjm.2021.v07i01.002

| Received: 16.12.2020 | Accepted: 31.12.2020 | Published: 08.01.2021

*Corresponding author: Dr. Saroja BG

Abstract

Original Research Article

Introduction: Hospital-acquired pneumonia (HAP) is the second most common nosocomial infection and has higher morbidity and mortality and prolongs hospital stay for patients and excess costs for them [1, 2]. Most significant factor associated with HAP is mechanical ventilation (MV) [1]. High risk MDR pathogens, sepsis, septic shock, elderly patients, bilateral infiltrates in chest $\mathrm{x}$ ray and co-morbidities are associated with, increases incidence of HAP and mortality. Methods: This prospective study was conducted in medical intensive care unit (MICU) and respiratory intensive care unit (RICU) of tertiary care teaching medical college hospital over a period of 18 months. 1554 cases were included in the study based on ATS/IDSA 2016 HAP guidelines. Objective: We studied clinical, radiological, bacteriological profile and factors affecting the outcome of HAP patients. During the study, we also analyzed causative organisms. Results: Out of 1554 patients, 194(12.5\%) patients developed HAP. Incidence of HAP among patients aged $>60$ years was 64\%. $132(68 \%)$ male patients and 62(32\%) female patients developed HAP. $124(22 \%)$ patients who were on mechanical ventilation had HAP. 52\% HAP cases had chronic respiratory illness. 16\% of HAP patients did not have any chronic systemic illness. Delirium was observed in most of the cases in higher age group. Bilateral infiltrates in chest $\mathrm{x}$ ray, sepsis, and septic shock are associated with high mortality. Most common organism isolated from sputum and endotracheal aspirate was Klebsiella pneumoniae. Conclusion: Incidence of HAP in this study was $12.5 \%$. Patients with higher age group and male gender were predominantly affected. Mechanical ventilation more than 48 hours, comorbidities, old age, bilateral infiltrates in chest X ray, sepsis, septic shock and multidrug resistant (MDR) pathogens are associated with high mortality. Early diagnosis, effective preventive and therapeutic strategies, aiming to decrease morbidity, mortality and optimize use of antimicrobial agents.

Keywords: Hospital-acquired pneumonia (HAP), Intensive care unit, Mechanical ventilation, respiratory intensive care unit, medical intensive care unit.

Copyright (C) 2021 The Author(s): This is an open-access article distributed under the terms of the Creative Commons Attribution 4.0 International License (CC BY-NC 4.0) which permits unrestricted use, distribution, and reproduction in any medium for non-commercial use provided the original author and source are credited.

\section{INTRODUCTION}

Hospital acquired pneumonia is the second most common nosocomial infection in intensive care unit $[1,2]$. HAP is the most common cause of mortality which ranges from 30 to $70 \%$ [3-5]. Incidence of HAP is higher in ICU acquired respiratory infection and it ranges from $9 \%$ to $28 \%$, variation is related to different ICUs [6, 12-15].

HAP is pneumonia occurring more than 48 hours after hospital admission and not incubating at the time of admission [7]. Ventilator associated pneumonia occurs after 48 to 72 hours of initiation of mechanical ventilation [7, 8]. Multiple risk factors are associated with increased incidence of HAP includes mechanical ventilation more than 48 hours, severity of underlying illness, presence of comorbidities and longer duration of stay in ICU $[4,9,18]$. The increasing incidence of HAP among patients on mechanical ventilation results in a significant increase in the cost of care of hospitalized patients and also prolongs hospital stay in ICU and consequently increases cost [10, 11]. Atypical presentation in elderly HAP patients is quite common and associated with higher mortality rate in this study and is consistent with the HAP mortality rate worldwide and it ranges from $30 \%$ to $70 \%$ [3-5].

\section{MATERIALS AND METHODS}

OBJECTIVE: To study clinical, radiological and bacteriological profile of hospital acquired pneumonia and factors affecting the outcome of HAP.

\section{Study period: 18 months}

Diagnosis of HAP was done on the basis of ATS/IDSA 2016 guidelines in the presence of both of the below,

1. Radiological criteria: new or progressive infiltrates in chest $\mathrm{x}$ ray 
2. Clinical criteria: at least two of the 3 clinical features (fever > 38 degree $\mathrm{C}$, leucocytosis or leucopenia with purulent secretions, decreased oxygenation)

\section{INCLUSION CRITERIA}

All patients admitted to MICU and RICU with age > 18 years showing signs and symptoms of pneumonia after 48 hours of hospitalization were included in the study after obtaining informed consent.

\section{EXCLUSION CRITERIA}

- Patients admitted with pneumonia

- Pregnant women

- Age less 18 years

- Radiological infiltrates due to pulmonary hemorrhage, pulmonary embolism, pulmonary edema, lung collapse, lung tumors, and patients with immunosuppression.

All patients $>18$ years of age who developed HAP in MICU \& RICU, as per inclusion and exclusion criteria were enrolled in the study. All patients were investigated clinically, radiologically and bacteriologically to determine the presence of pneumonia and isolate causative micro-organisms. Investigations such as CBC, RFT, LFT, CRP, FBS/PPBS and arterial blood gas analysis done. Blood, urine, sputum and endotracheal aspirate were sent for culture and sensitivity. Chest x ray/ HRCT thorax was taken. Empherical antimicrobials initiated and shifted to specific antibiotic according to culture and sensitivity reports. All patients were followed until the time of discharge or death.

\section{RESULTS}

During the study period of 18 months, 1644 patients were admitted to MICU \& RICU. 90 patients were excluded from the study as per inclusion \& exclusion criteria. 1554 cases were included in the study. Out of 1554 cases, 901(58\%) were male and $652(42 \%)$ were female. Age of the study population ranged from 18 to 80 years. 194(12.5\%) developed HAP. $125(64 \%)$ cases developed HAP were in the age group >60 years. $132(68 \%)$ male patients and 62(32\%) female patients developed HAP. High incidence of HAP observed in male patients and in higher age group.

Table-1: Pattern of age \& gender distribution of patients with HAP

\begin{tabular}{|l|l|l|l|}
\hline AGE (YEARS) & MALE & FEMALE & TOTAL \\
\hline $\mathbf{1 8}-40$ & $\mathbf{1 0}$ & $\mathbf{5}$ & $\mathbf{1 5}$ \\
\hline $41-60$ & 35 & 19 & 54 \\
\hline$>60$ & 87 & 38 & 125 \\
\hline TOTAL & 132 & 62 & 194 \\
\hline
\end{tabular}

Table-2: Clinical features in patients with HAP

\begin{tabular}{|l|l|c|}
\hline SYMPTOMS \& SIGNS & NUMBER & $\%$ \\
\hline BREATHLESSNESS & 112 & 58 \\
\hline $\begin{array}{l}\text { COUGH WITH } \\
\text { EXPECTORATION }\end{array}$ & 80 & 41 \\
\hline DELIRIUM & 78 & 40 \\
\hline FEVER & 72 & 37 \\
\hline HAEMOPTYSIS & 30 & 15 \\
\hline CHEST PAIN & 22 & 11 \\
\hline
\end{tabular}

112(58\%) patients had breathlessness. $80(41 \%)$ patients had cough with purulent expectoration. $78(40 \%)$ patients presented with delirium which was the most predominant sign noted in most of elderly patients and most of them did not have cough or fever. Some of the patients also had haemoptysis and chest pain.

Table-3: Risk factors associated with HAP

\begin{tabular}{|l|l|l|}
\hline CO-MORBIDITIES & NUMBER & $\mathbf{\%}$ \\
\hline COPD & 28 & 15 \\
\hline BRONCHIAL ASTHMA & 16 & 8 \\
\hline BRONCHIECTATSIS & 12 & 6 \\
\hline COPD WITH DIABETES & 18 & 9 \\
\hline ASTHMA WITH DIABETES & 16 & 8 \\
\hline COPD WITH HYPERTENSION & 11 & 6 \\
\hline DIABETES & 10 & 5 \\
\hline HYPERTENSION & 8 & 4 \\
\hline DIABETES WITH HYPERTENSION WITH IHD & 8 & 4 \\
\hline DIABETES WITH CHRONIC KIDNEY DISEASE & 5 & 3 \\
\hline LIVER DISEASE & 8 & 4 \\
\hline NEUROLOGICAL EVENTS & 4 & 2 \\
\hline CARDIAC CAUSES & 12 & 6 \\
\hline POISONING & 8 & 4 \\
\hline NO CO-MORBIDITIES & 30 & $16 \%$ \\
\hline
\end{tabular}

Table 3 shows majority (52\%) of study population had chronic respiratory illness followed by diabetes (29\%) and other systemic illnesses. 30 (16\%) of HAP patients didn't have any co-morbidities. 
Saroja BG., SAS J Med, Jan, 2021; 7(1): 4-8

According to chest $\mathrm{x}$ ray and HRCT thorax reports of HAP patients, $54(28 \%)$ had infiltrates in single lobe, 62(32\%) cases had infiltrates in 2 lobes and
$78(40 \%)$ cases had infiltrates in 3 or more lobes. Bilateral infiltrates seen in $52 \%$ of patients.

Table-4: Influence of mechanical ventilation on HAP

\begin{tabular}{|l|l|l|l|}
\hline DETAILS OF PATIENT & VENTILATED & NON-VENTILATED & TOTAL \\
\hline PATIENTS IN MICU +RICU & 568 & 986 & 1554 \\
\hline PATIENTS WITH HAP & 124 & 70 & 194 \\
\hline
\end{tabular}

Out of 1554 patients, $568(37 \%)$ cases were on mechanical ventilation out of which $124(22 \%)$ developed HAP. 70 (7\%) cases developed HAP among $986(63 \%)$ cases who were not on mechanical ventilation. Out of 194 HAP cases, 128(64\%) had ventilator associated pneumonia and $70(36 \%)$ cases had HAP among non-ventilated patients.

Table-5: Incidence of sepsis, septic shock and mortality in patients with HAP

\begin{tabular}{|l|l|l|l|l|}
\hline $\begin{array}{l}\text { DETAILS OF } \\
\text { PATIENTS }\end{array}$ & \multicolumn{2}{|l|}{ SEPSIS } & \multicolumn{2}{l|}{ SEPTIC SHOCK } \\
\hline & NUMBER & $\%$ & NUMBER & $\%$ \\
\hline NUMBER \& \% & 62 & 32 & 29 & 15 \\
\hline RECOVERED & 34 & 55 & 12 & 41 \\
\hline DEATH & 28 & 45 & 17 & 59 \\
\hline
\end{tabular}

Out of 194 cases, 62 developed sepsis, 28 died and $55 \%$ of the cases recovered. 29 patients had septic shock, $41 \%$ of them recovered and 59\% died. Higher incidence of morbidity seen among HAP patients with sepsis and septic shock. Out of 194 HAP patients, $130(67 \%)$ cases recovered and 64 (33\%) cases succumbed to the illness.

\section{DISCUSSION}

The incidence of HAP in this study was $12.5 \%$ which correlated with various studies in which incidence of HAP ranges from $9 \%$ to $28 \%$ [6, 12-15]. Variation in incidence may be due to different patient subsets in different ICUs, different diagnostic technique, and standard management protocol of different ICUs etc. $64 \%$ of the patients belonged to the age group above 60years. Incidence of HAP is more in higher age group than younger age group, same was reported in Berba et al. [14], higher the age risk of HAP is greater, was reported in earlier studies (16 .17) Our study noted high incidence of HAP in males compare to females which is in accordance with other studies too $[13,18]$.

Most common signs and symptoms observed in this study were breathlessness, cough with purulent expectoration, delirium and fever. Few cases also reported haemoptysis and chest pain. Delirium was observed in large number of elderly patients and was associated with poor outcome. Similar findings seen by Alberti et al. [19]. Majority of elderly patients in the study did not have fever or respiratory symptoms; the atypical presentation makes it difficult for physicians to diagnose [20].
Various comorbidities were present in most of our study patients. 52\% had chronic respiratory illness, $29 \%$ had diabetes and other clinical diseases contributed for rest of predisposing factors. In the present study it was noted that the prevalence of chronic respiratory illness was $52 \%$ and COPD $29 \%$ which is lower than reported in the study conducted in JIPMER [21] in which prevalence of chronic respiratory illness was $72 \%$ and COPD was $42 \%$. Pre-existing respiratory co-morbidity is a risk factor for development of HAP. Other risk factors associated with HAP are shown in the table 3. Most of the HAP patients who expired had bilateral infiltrates in chest $\mathrm{x}$ ray, similar results found in study by WUDERINE RG et al. [22].

Predominant pathogen isolated from sputum and ET aspirate was Klebsella Pneumoniae (30\%) closely followed by Pseudomonas Aeruginosa (22\%), MRSA (18\%), polymicrobes (12\%), Acinetobacter SPP (10\%), E COLI (8\%). Klebsella Pneumoniae \& MRSA were most commonly isolated organisms according to microbial prediction of ATS/IDSA 2005 and in review article done by CHOA-HSIEN LEE et al. in 2008 [23]. In our study Klebsella Pneumoniae (30\%) was predominantly isolated which is similar to the findings of other studies 23,27. Multi drug pathogens were also observed in this study. Most of the patients who expired had MDR pathogens, this result in accordance with other studies [24].

Hospital acquired pneumonia was higher among the patients on prolonged MV. Incidence of ventilator associated pneumonia was $64 \%$ among the HAP patients, and is lower than the other studies [25] in which $75.5 \%$ of all patients with HAP were VAP. Mortality was greater among the patients on MV > 48 hours. MV definitely carries high risk for increased incidence of HAP and associated with highest mortality. HAP is associated with highest mortality rate of all nosocomial infection which is estimated to be between 35 to $56 \%$ globally [26].

\section{CONCLUSION}

HAP is the nosocomial infection in ICU. The incidence of HAP in this study was $12.5 \%$ which is within the range seen in studies conducted worldwide. In this study majority of HAP found in elderly patients and in male gender. It is important to have history of patients, comorbidities, immunosuppressive disease and medications which are risk factors which could predispose the patients to HAP. Atypical presentation in 
older patients with HAP is quite common. Our study showed increased risk of HAP among patients with chronic respiratory illnesses such as COPD, asthma and bronchiectasis. Higher incidence of HAP among patients on mechanical ventilation for more than 48 hours proved to be highest risk factor and associated with high mortality. Predominantly isolated organisms from sputum and ET aspirate were gram negative organisms, MRSA, polymicrobes. MDR pathogens were associated with high mortality. MV >48 hours, pre-existing co-morbidities, higher age, bilateral infiltrates in chest $\mathrm{x}$ ray, sepsis, septic shock, and high risk MDR pathogens carry poor prognosis.

Inference from the present study is to reduce incidence of HAP and mortality due to HAP, avoid unnecessary prolonged hospitalization, MV of patients; consider non-invasive ventilation whenever possible. Knowledge of risk factors, atypical presentation of HAP in elderly patients, to have adequate staff in ICUs, implementing strict hospital infection control policy, knowledge of prevalence of organisms and sensitivity pattern in ICUs' helps in taking important preventive measures and choosing appropriate empherical treatment which reduces subsequent HAP and its mortality.

\section{REFERENCES}

1. George L. Epidemiology of Pneumonia in intensive care unit Patients. Clin Chest Med. 1995; 16: 2944.

2. Jarvis WR et al. Nosocomial infection rates in intensive care units in the United States; Nnis.Am J Med Br. 1991; 91:1855.

3. Ranjan $\mathrm{N}$ et al. Ventilator-associated Pneumonia in tertiary care intensive care unit: Analysis of incidence, risk factors and mortality. Ind J Crit Care Med. 2014; 18:200-4.

4. Rit $\mathrm{K}$ et al. Ventilator associated Pneumonia in tertiary care hospital in India: Incidence, etiology, risk factors, role of multi drug pathogens. Int J Med Public Health. 2014; 4:51-6.

5. Gadani H et.al. A Study of Ventilator-associated Pneumonia: Incidence, outcome, rIsk factors and measures to be taken for Prevention. Indian $\mathbf{J}$ Anaesth. 2010; 54:535-40.

6. Merchant $\mathrm{M}$ et al. Incidence of nosocomial pneumonia in medical intensive care unit and general medical ward patients in a public hospital in Bombay. India. J Hosp Infect. 1998; 39; 143-8.

7. Guidelines for the management of adults with Hospital-acquired and Ventilator-associated Pneumonia. Am J Resp Crit Care Med. 2005; 17; 388-416.

8. Chastre $\mathbf{J}$ and Fogon JY. Ventilator-associated Pneumonia. Am J Respir Crit Care Med. 2002; 165:867-903.

9. American Thoracic Society, Infectious disease society of America guidelines for the management of adults with Hospital acquired, Ventilator- associated and Health care associated Pneumonia. Am J Respir Crit Care Med. 2005; 171:388-416.

10. File TM. Hospital acquired (Nosocomial) pneumonia in adults. Update. 2006; 15:1.

11. Davis KA. Ventilator-associated Pneumonia: a review. J Intensive Care Med-2006;21:211-26.

12. Trived TH et al. Nosocomial Pneumonia in medical Intensive Care Unit. J Assoc Physicians India. 2006;48(1):1070-3.

13. Vasuki V et al. Clinical profile of Hospital acquired Pneumonia in a Tertiary Care Hospital.South India. Int J Res Med Sci. 2016;4(6):1841-1844.

14. Berba $\mathrm{R}$ et al. Incidence, risk factors and outcome of Hospital-acquired Pneumonia in Critically ill patients at the Philippine General hospital. Phil J Microbiol Infect Dis. 199;28(2):29-38.

15. Rozaidi SW et al. The incidence of Nosocomial infection in the intensive care unit.Hospital Univarsiti Kebangsaon. Malaysia; Intensive care unit acquired Nosocomial Infection.Survivallence program. 1998-1999. Med J Malayasia. 2001; 56:207-22.

16. Hunter JD. Ventilator-associated Pneumonia. J post grad med. 2006;82:172-8.

17. Celis R, Torres A, Gatell JM, Almela M, Rodríguez-Roisin R, Agustí-Vidal A. Nosocomial pneumonia: a multivariate analysis of risk and prognosis. Chest. 1988 Feb 1;93(2):318-24.

18. López-Mestanza C, Andaluz-Ojeda D, GómezLópez JR, Bermejo-Martín JF. Clinical factors influencing mortality risk in hospital-acquired sepsis. Journal of Hospital Infection. $2018 \mathrm{Feb}$ 1;98(2):194-201.

19. Aliberti S, Bellelli G, Belotti M, Morandi A, Messinesi G, Annoni G, Pesci A. Delirium symptoms during hospitalization predict long-term mortality in patients with severe pneumonia. Aging Clinical and Experimental Research. 2015 Aug 1;27(4):523-31.

20. Metlay JP, Schulz R, Li YH, Singer DE, Marrie TJ, Coley CM, Hough LJ, Obrosky DS, Kapoor WN, Fine MJ. Influence of age on symptoms at presentation in patients with community-acquired pneumonia. Archives of Internal Medicine. 1997 Jul 14;157(13):1453-9.

21. Charles MP, Easow JM, Joseph NM, Ravishankar M, Kumar S, Umadevi S. Incidence and risk factors of ventilator associated pneumonia in a tertiary care hospital. The Australasian Medical Journal. 2013;6(4):178-182.

22. Woundrit R.G et al. The radiologic diagnosis auto psu Prouen for associated pneumonia chest.1992:101(2):458-63.

23. Lee $\mathrm{CH}, \mathrm{Wu} \mathrm{CL}$. An update on the management of hospital-acquired pneumonia in the elderly. International Journal of Epidemiology. 2008 Dec 1;2(4):183-95.

24. Joseph NM, Sistla S, Dutta TK, Badhe AS, Rasitha D, Parija SC. Ventilator-associated pneumonia in a tertiary care hospital in India: role of multi-drug 
resistant pathogens. The Journal of Infection in Developing Countries. 2010 Jan 18;4(04):218-25.

25. Alp E, Güven M, Yildız O, Aygen B, Voss A, Doganay M. Incidence, risk factors and mortality of nosocomial pneumonia in intensive care units: a prospective study. Annals of Clinical Microbiology and Antimicrobials. 2004 Dec 1;3(1):17.

26. Chawla R. Epidemiology, etiology, and diagnosis of hospital-acquired pneumonia and ventilator- associated pneumonia in Asian countries. American Journal of Infection Control. 2008 May 1;36(4):S93-100.

27. Varghese DC, Gopinath D, Suhail N. ClinicoBacteriological Profile and Prognostic Factors of Hospital Acquired Pneumonia in Central Kerala. Galore International Journal of Health Sciences and Research. 2020;5(2):41-8. 